\title{
Subconjunctival Air Leakage After Descemet's Stripping Automated Endothelial Keratoplasty(DSAEK) in a Post-Trabeculectomy Eye
}

\author{
Takeshi Ide, Sonia H. Yoo", Theodore Leng and Terrence P. O'Brien
}

Bascom Palmer Eye Institute, University of Miami, Miami, FL, USA

\begin{abstract}
Purpose: To report a case of subconjunctival air leakage from the anterior chamber (AC) into a trabeculectomy bleb after Descemet's stripping automated endothelial keratoplasty (DSAEK).

Methods: An 89 year-old woman with a previous history of primary open angle glaucoma in her left eye and previous trabeculectomy with mitomycin C had DSAEK on the patient's left eye in order to treat her endothelial disease. During the DSAEK procedure, air was injected into the AC to aid in graft adherence.

Results: The day after the surgery, subconjunctival air leakage from the AC into a trabeculectomy bleb was observed.

Conclusion: Although our patient did not have any complications from this leak, there exists the potential for hypotony, bleb-related infections, and dislocations of the DSAEK graft. Given the potential consequences, these patients should be monitored closely.
\end{abstract}

\section{INTRODUCTION}

Descemet's stripping automated endothelial keratoplasty (DSAEK) is currently the most popular method for selective endothelial keratoplasty [1-3]. Fewer complications are expected when posterior corneal tissue is selectively replaced because full thickness penetrating keratoplasty (PKP) can be complicated by a variety of postoperative problems and can lead to corneal structural instability. Currently, most surgeons utilize an air bubble to tamponade donor corneal tissue to the host cornea at the conclusion of DSAEK procedures. In this case report, we aim to report a case of subconjunctival air leakage from the anterior chamber (AC) into a trabeculectomy bleb after DSAEK.

\section{CASE DESCRIPTION}

An 89 year-old woman with a previous history of primary open angle glaucoma in her left eye and previous trabeculectomy with mitomycin C (MMC) presented to our clinic with bullous keratopathy and band keratopathy. Her intraocular pressure (IOP) was well controlled $(10 \mathrm{mmHg})$ with a topical beta-blocker. The remainder of her ophthalmic and general exam was otherwise normal. We performed DSAEK on the patient's left eye in order to treat her endothelial disease.

At the end of her routine and uneventful DSAEK surgery, sterile filtered air was injected into the AC to tamponade the donor graft into position. On post-operative day one, slit lamp examination revealed subconjunctival air leakage inside the trabeculectomy bleb (Fig. 1). The DSAEK graft was well centered and adherent to the host stoma with a $50-60 \%$ air fill remaining. IOP measured $14 \mathrm{mmHg}$ and the remainder of her ocular exam was within normal limits.

*Address correspondence to this author at the Bascom Palmer Eye Institute, 900 NW 17th Street, Miami, FL 33136, USA; Tel: +1 305326 6322;

Fax: +1 305326 6337; E-mail: syoo@med.miami.edu

\section{DISCUSSION}

DSAEK is an effective means for endothelial keratoplasty that preserves structural integrity of the cornea. Currently, an $\mathrm{AC}$ air bubble is used to tamponade the graft into the proper position in most cases. In a patient who has a functional filtering bleb, it is possible for the $\mathrm{AC}$ air to travel through the filter and into the conjunctival bleb.

There are several potential complications stemming from air movement from the $\mathrm{AC}$ into the trabeculectomy bleb. First, the DSAEK procedure could fail. Air is injected into the AC to tamponade and position the DSAEK graft into the proper anatomic location. If enough air is not left in the $\mathrm{AC}$, there is a potential for graft dislocation and DSAEK failure, though some doctors now remove the air from the AC just before completion of the procedures [4]. Additionally, air travelling though a trabeculectomy filter may lyse functional adhesions that have formed and alter the rate of aqueous filtration through the bleb. This could result in overfiltration, a flat $\mathrm{AC}$, and hypotony. If the $\mathrm{AC}$ becomes very shallow, there is a possibility of iris-cornea touch that could damage the newly transplanted endothelium affect the success of the DSAEK surgery.

Subconjuctival air bubble could also lead to an increased risk of bleb-related infections due to an enlarged tract and an increased flow rate between the $\mathrm{AC}$ and the conjunctival bleb. Lastly, a large amount of air could cause avascular mitomycin $\mathrm{C}$ treated blebs it to fail due to barotraumas or overfiltration.

Even without any pressure from subconjunctival air, early- and late-onset bleb leak and its associated hypotony are among the most common complications after trabeculectomy $[5,6]$.

Although our patient did not suffer any of these potential complications and the air spontaneously resolved, one should follow similar patients closely to monitor for these changes. 


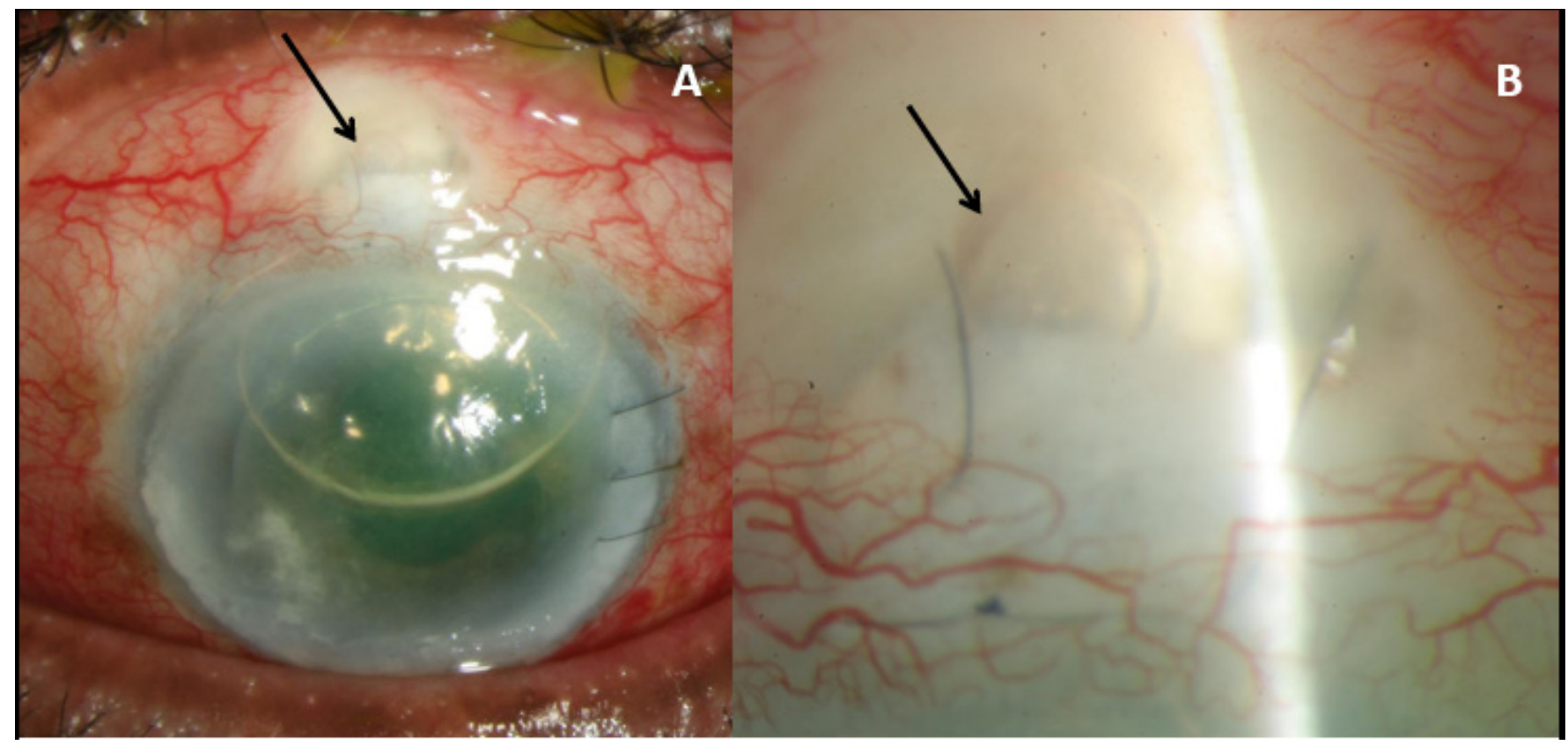

Fig. (1). Low (A) and high power (B) slit lamp photographs of the left eye on post-operative day one demonstrates subconjunctival emphysema (arrows) in the trabeculectomy bleb after Descemet's stripping automated endothelial keratoplasty (DSAEK).

Some authors have suggested that air may be toxic to endothelium [7, 8]. Therefore, the optimal solution may be to forgo the use of any AC air in patients who have a functional filtering bleb; however, the risk of post-operative DSAEK graft dislocation may increase.

$$
\begin{array}{ll}
\text { ABBREVIATIONS } & \\
\text { DSAEK }= & \begin{array}{l}
\text { Descemet's stripping automated endothelial } \\
\text { keratoplasty }
\end{array} \\
\mathrm{PKP}= & \text { Penetrating keratoplasty } \\
\mathrm{AC} \quad= & \text { Anterior chamber } \\
\mathrm{IOP} \quad= & \text { Intraocular pressure } \\
\mathrm{MMC}= & \text { Mitomycin } \mathrm{C}
\end{array}
$$

\section{REFERENCES}

[1] Fang JP, Hamill MB. Descemet's stripping endothelial keratoplasty under topical anaesthesia. J Refract Surg 2007; 33: 187-8.

[2] Koenig SB, Covert DJ. Early results of small-incision Descemet's stripping and automated endothelial keratoplasty. Ophthalmology 2007; 114: 221-6.

[3] Price FW Jr, Price MO. Descemet's stripping with endothelial keratoplasty in 200 eyes: Early challenges and techniques to enhance donor adherence. J Refract Surg 2006; 32: 411-8.

[4] Terry MA. Endothelial keratoplasty: history, current state, and future directions. Cornea 2006; 25: 873-8.

[5] Spencer NA, Lee C, Diamond JP. Combined conjunctival relieving incisions and advancement for the repair of late-onset leaking trabeculectomy blebs. J Glaucoma 2007; 16: 384-7.

[6] Troutbeck R, Lee GA, Sanfilippo P, Fleming B. Trabeculectomy: a training dilemma. Eye 2007; 21: 183-6.

[7] Olson RJ. Air and the corneal endothelium: An in vivo specular microscopy study in cats. Arch Ophthalmol 1980; 98: 1283-4.

[8] Kerr Muir MG, Sherrard ES, Andrews V, et al. Air, methylcellulose, sodium hyaluronate and the corneal endothelium. Endothelial protective agents. Eye 1987; 1(Pt 4): 480-6.

(C) Ide et al.; Licensee Bentham Open.

This is an open access article licensed under the terms of the Creative Commons Attribution Non-Commercial License (http: //creativecommons.org/licenses/by$\mathrm{nc} / 3.0 /$ ) which permits unrestricted, non-commercial use, distribution and reproduction in any medium, provided the work is properly cited. 